\title{
A cidade no fluxo do tempo: invenção do passado e patrimônio
}

IRLYS ALENCAR F. BARREIRA*

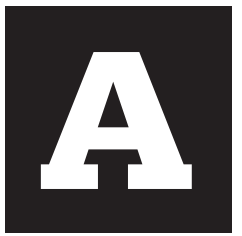

cidade de Fortaleza, na década de 1990, é palco de um duplo fenômeno. De um lado, as grandes transfigurações urbanísticas, que já se anunciam desde 1970, repetem o que parece ser o destino da maioria das metrópoles brasileiras. De outro, discursos sobre a conservação de espaços e edificações apontam a necessidade de resguardar a "história da cidade". Revitalizar o decadente e preservar o antigo constituem lemas de gestores políticos, planejadores urbanos, ou candidatos ao pleito municipal, preocupados em conter a marcha do "todo sólido que se desmancha".

O princípio de revitalização dos centros históricos e a instauração de pontos turísticos não se restringem, evidentemente, a Fortaleza, sendo comum a cidades brasileiras marcadas por processos acelerados de mudança. Basta lembrar algumas cidades do Nordeste: o Pelourinho, em Salvador; os centros históricos de Recife, São Luís, e João Pessoa. O crescimento urbano das cidades ou o conjunto de processos convencionalmente nomeados de "modernização" aparecem, nesse sentido, acompanhados de investimentos materiais e simbólicos em torno da manutenção e restauração de equipamentos, percebidos como expressão do patrimônio das cidades.

* Professora da Universidade Federal do Ceará - UFC.

1 Alusão à frase de Marx que serve de título ao livro de Marshal Berman, Tudo que é sólido se desmancha no ar: a aventura da modernidade, São Paulo, Companhia das Letras, 1982. 
As transformações citadinas, que, na realidade, traduzem processos urbanos de mudança, efetivam-se tendo por referência diferentes discursos. Discursos que são fundamento de intervenções ou críticas de cunho social feitas por intelectuais e estudiosos da temática, normalmente dirigidas aos representantes do poder estadual e municipal.

Repensar a cidade sob a ótica de sua "memória" ou sob o prisma de significados atribuídos à noção de patrimônio supõe compreender a lógica das prioridades sobre o uso e valorização de espaços efetivados ao longo do tempo. Prioridades que aparecem como coletivamente construídas, embora sejam objeto permanente de disputas simbólicas que revelam interesses de diferentes atores sociais. O que preservar, como mudar ou o que mudar são questões que vêm à tona atualmente com mais evidência, alimentando o plano das representações sobre a cidade, que orientam diferentes discursos.

O conjunto de intervenções, discursos e depoimentos formadores de opinião sobre os processos urbanos contemporâneos em Fortaleza caracterizam o que nomeio de "diálogo entre passado e presente". Trata-se de uma metáfora que visa apontar as diferentes formas de evocar o passado, visto tanto sob a óptica de um tempo mítico e sem retorno como na perspectiva de um tempo inventado e vivido em continuidade com os usos contemporâneos do espaço urbano. Com isso, quero dizer que a "história ou memória da cidade", materializadas no conceito de patrimônio, expressam versões diferenciadas ou visões de um imaginário ${ }^{2}$ urbano, nem sempre convergentes.

Os discursos sobre a cidade estão circunstanciados a diferentes contextos e múltiplas interlocuções. Destacam-se, nesse sentido, depoimentos e falas sobre a cidade efetivados por cronistas, historiadores, políticos e profissionais do planejamento urbano. A urbe tem sido, dessa forma, pon-

2 Para o conceito de imaginário ver, entre outros, Cornelius Castoriadis, A instituição imaginária da sociedade, Rio de Janeiro, Paz e Terra, 1992 e François Laplantine, Les trois voix de I'imaginaire, Paris, Éditions Universitaire, 1974. 
to de referência para se nomear a vida social moderna com seus problemas e utopias.

Se a cidade que emergiu junto com o capitalismo acenou com ares de liberdade e ruptura com o passado, a vida contemporânea citadina aparece muitas vezes como promessa não realizada. Um lugar de opressão, conflito e violência que põe a tradição no roteiro de uma nova funcionalidade: restauram-se pontes, espaços, casas, monumentos. Tudo parece evocar um necessário tempo de volta.

As metamorfoses atuais pelas quais passa a cidade, na sociedade contemporânea, ensejam freqüentemente discursos alusivos a diferentes temporalidades. O espaço e a vida urbanos aparecem como se fossem submetidos a sucessivas perdas que remontam à nostalgia de um tempo anterior, de maior sociabilidade e intimidade entre os indivíduos, tal como apontou Simmel em seu estudo sobre a metrópole e a vida mental (1976). O tempo anterior sinalizaria o momento no qual era possível ter controle sobre os processos citadinos, incluindo a comunicação entre os habitantes.

Esta representação do passado nem sempre se apóia em uma concepção de irreversibilidade. David Harvey, por exemplo, indaga como é possível

construir a próxima camada no palimpsesto urbano, de forma a canalizar aspiraçôes e necessidades futuras, sem violentar em demasia tudo o que já foi feito antes. Parte do legado do passado terá que ser obviamente descartado. Construçóes degradadas e em ruínas certamente devem ser demolidas e locais abandonados merecem uma revitalização (Harvey, 1996, p. 171).

O autor prossegue em suas reflexões, argumentando sobre os efeitos da tecnologia na modificação e ampliação de espaços e as conseqüentes reações indutoras da recuperação de um lugar e um sentimento de pertença. A perspectiva geral de Harvey é a de pensar na criação de algo 
novo, construído de forma socialmente responsável, sem violentar em demasia o que existia antes.

As cidades brasileiras, de modo geral, podem também ser objeto desta complexa reflexão que emerge no final do século XX, não obstante a diversidade de situações que as caracterizam. Para pensar o tema das representações e linguagens sobre a cidade, tomarei como referência Fortaleza que talvez, nesse momento, expresse com nitidez uma multiplicidade de discursos articulados a formas variadas de intervenção urbana. Os discursos construídos sobre a cidade e o modo de evocar o passado, articulando-o a funções presentes, constituem o cerne fundamental das reflexões aqui delineadas. Em termos de material de pesquisa, serão considerados artigos de jornais, romances sobre Fortaleza, entrevistas, programas televisivos, propagandas eleitorais e documentos que têm como referência o contexto urbano da capital cearense. Muitas das reflexões podem, no entanto, apontar questões vivenciadas por diferentes cidades no período designado por diferentes analistas como pós-modernidade.

\section{As cidades como campo de representação simbólica}

As cidades, com seus dilemas e utopias, têm sido palco de representações discursivas em várias dimensões criativas da vida social. Desde a mitologia religiosa, que separa as cidades malditas (Sodoma, Gomorra), das redentoras (Jerusalém, Roma), passando pela cidade justa de Platão, ou as tenebrosas dos contos de Edgar Alan Poe, observa-se que o espaço urbano condensa um conjunto de significações imaginárias. No contexto mais recente da chamada "pós-modernidade", as cidades aparecem habitadas por novas dinâmicas de violência e poder, reveladas em formas de sociabilidade e conflito, incluindo também diferentes expressões culturais (Harvey, 1993; Jameson, 1994; Featherstone, 1995). 
Discutir as representações alusivas à cidade supõe uma indagação anterior: em que sentido é possível pensar em construções discursivas sobre a cidade? Wittgenstein (1996), ${ }^{3}$ nesse sentido, elabora uma homologia entre cidade e linguagem:

... e quantas casas e ruas são necessárias para que uma cidade comece a ser uma cidade? Nossa língua pode ser vista como uma cidade antiga: um labirinto de pequenas ruas e praças, de casa velhas e novas, e de casas com extensões construídas em vários períodos; $e$ tudo isso circundado por uma profusão de áreas modernas, com ruas regulares e retas e casas uniformes.

A metáfora da cidade como linguagem suscita o tema dos signos e investimentos culturais que integram diferentes espacialidades. Nesse sentido, os discursos literários, artísticos e depoimentos difundidos nos meios de comunicação de massa constituem registros dos dramas da cidade, suas transformações, perdas e utopias (Canclini, 1997).

Na escrita literária, nas interpelações de planejadores e na reflexão filosófica, encontram-se modelos de constituição das metrópoles, que aparecem como espaços paradigmáticos que traduzem a sociedade em variados momentos. As cidades, com seus temores, com acenos de liberdade ou opressão ocuparam, assim, parte significativa do pensamento social, permeando não somente elaborações teóricas, mas também propostas de intervenção envolvendo aqueles que tomavam por tarefa dirigir os seus destinos. A cidade foi o palco de referência do pensamento sociológico clássico, sendo o locus a partir do qual se pensava o mundo social. As categorias de espaço e tempo, na reflexão sociológica contemporânea, fundamentam-se também no aglomerado urbano, a exemplo do conceito de poder disciplinar, em Foucault ou de esfera pública, em Habermas, vista como a antítese da corte e lugar de concentração das instituições.

3 ApudClifford Geertz, O saber local: novos ensaios de antropologia interpretativa. Petrópolis: Vozes, 1999, p. 111. 
O imaginário sobre as cidades, evocado em diferentes situações, constitui um rico caminho analítico para se pensar o modo como as circunstâncias históricas viabilizam projeções de sociabilidade urbana, sendo o passado ou o futuro as fontes de referência por onde se constroem o "paraíso perdido" ou a visão da "nova sociedade". Contemporaneamente um dos aspectos que vão configurar a perspectiva de cidade idealizada, é a possibilidade de assumi-la como projeto de gestão. A cidade emerge como "sujeito político" supondo, na concepção de Castells (1996), a vigência de atores capazes de intervir e de definir práticas coletivas com base em decisões democráticas.

As cidades aparecem também, no contexto mais recente, como lugar de articulação de interesses econômicos e tecnológicos, apresentando uma revalorização de espaços internos considerados como fontes de investimentos vindos de vários campos da atividade social. É nesse contexto que se revela a cidade-síntese que, de acordo com a pesquisa de Ribeiro e Garcia (1996) feita em Curitiba, expressa um território conjugado de práticas baseadas em interesses econômicos e políticos acompanhados de investimentos simbólicos que lhes servem de suporte.

Imagens da cidade a serem consumidas são também indutoras de especializações que atuam como amostra de "vocações". Surgem, assim, as cidades turísticas, aquelas voltadas para o trabalho, as cidades da cultura, entre outras. As cidades contemporâneas parecem expressar, de modo mais nítido, um conjunto de representações e disputas materiais e simbólicas evidentes em momentos específicos de intervenção urbana e em situações de concorrência política, a exemplo das campanhas eleitorais municipais. Acenos diversos oriundos de organizações populares, com demandas de participação, são também constitutivos de versões que objetivam tornar a cidade "democrática", em oposição às dualidades que caracterizam grande parte das metrópoles brasileiras. 


\section{A "invenção das tradições" na cidade}

No curso das transformações atuais do espaço urbano, percebe-se que a recuperação de locais e tradições que compõem a "história" de diferentes cidades emerge com intensidade. As cidades parecem construir "palavras de ordem" referentes à preservação, antes que o passado fique apenas retido em memória longínqua, sem o monumento objetivo de referência. Subjacente às estratégias de conservação de espaços, considerase tanto a valorização das "ruínas" como a chamada revitalização que, muitas vezes, aponta a recuperação de usos coletivos dotados de novas funções, sobretudo voltadas para o lazer ou para consumo cultural.

Recuperar o passado não é, entretanto, repetir o tempo, mas reinventálo. ${ }^{4}$ Diferente dos usos pioneiros, os equipamentos urbanos viram espécie de "museus", readquirindo, no entanto, novas funções sociais ou políticas. A própria idéia de patrimônio significa a tentativa de "contar" o passado adaptando-o à nova linguagem do presente. Não deixa de ser sintomático que o centro da maioria das cidades nordestinas seja, neste momento, alvo de remodelação. Recupera-se o antigo café, o bar, o teatro, a casa de prostituição dotada de uma nova função, e com isso, pensa-se deter a marcha destrutiva da expansão e reformulação de equipamentos urbanos. No plano das sociabilidades, objetiva-se reaver formas anteriores de comunicação coletiva. As velhas praças, lugarejos e sentidos herdados de uma tradição cultural são reativados e se tenta, com isso, recompor antigas referências associativas, solapadas por uma modernidade que tornou a cidade funcional para o desempenho das atividades produtivas, mas bastante problemática para o convívio humano.

A busca de ativar costumes do passado encontra-se exemplificada no discurso do arquiteto Fausto Nilo, responsável pela reforma e recuperação de vários espaços urbanos: ${ }^{5}$

4 Ver Hobsbawm, Eric e Ranger Terence, A invenção das tradições. Rio de Janeiro: Paz e Terra, 1984.

5 Destacam-se entre suas obras mais recentes a reforma da Praça do Ferreira, situada no centro da cidade, A Reforma da Ponte dos Ingleses e O Centro Dragão do Mar, entre outras. 
Fortaleza é uma cidade com poucas tradições. A minha proposta é a de recuperar um pouco dos hábitos dos cidadãos e criar um contexto paisagístico que possibilite o consumo cultural e que tenha espaços amplos. O centro Dragão do Mar tenta aproveitar a luz do sol, as paredes brancas, a natureza, oferecendo também ao cidadão o consumo casual. Ele passa por determinados lugares e se sente atraído por determinados bens culturais. Fortaleza é uma cidade onde as pessoas têm poucos hábitos culturais. A idéia é então de criar uma oferta e induzir um tipo de consumo (Entrevista concedida à autora em maio de 1999).

A perspectiva de ressignificar e criar novos usos para o espaço urbano expressa a procura de uma relação mais orgânica entre passado e presente. As críticas a respeito da desfiguração do espaço urbano e a busca de recompor a "história" da cidade através de uma política de preservação do patrimônio surgem nas últimas décadas em Fortaleza, coincidindo com um grande aumento de edifícios e áreas específicas de lazer e comércio típicos das metrópoles. A "revitalização" do centro da cidade e o tombamento dos antigos prédios respondem a esse fluxo dialético de transformação e preservação que caracteriza parte significativa das cidades brasileiras.

A chamada "invenção das tradições", em Fortaleza, não acontece sem um suporte histórico de referência. Neste sentido, é importante uma breve caracterização da cidade. A elevação do povoado à categoria de vila aconteceu em 1726 no dia 13 de abril, data que se tornou espaço anual de comemoração e discussão sobre a história da cidade, reunindo opiniões de especialistas, largamente difundidas na imprensa. Com crescimento acentuado a partir do século XIX, Fortaleza torna-se capital, sendo não só centro político do Estado, mas centro econômico, com o comércio de 
exportação do algodão e importação de bens manufaturados. A cidade configura-se então, cada vez mais, como moderna, seja por seu traçado urbano ou pela ampliação de serviços e transportes.

É interessante observar, analisando-se a remodelação urbana de Fortaleza na virada do século XIX, que a crença no progresso parece subsidiar as estratégias reguladoras da intervenção urbana. A reforma de praças tradicionais do centro da cidade responde, nesse momento, ao fluxo crescente de uma cidade em expansão. Na perspectiva do arquiteto Liberal de Castro, as reformas urbanas alinhavam-se com aquelas produzidas na Europa, a exemplo de estilos arquitetônicos adotados. Este discurso de progresso e modernidade torna-se também hegemônico nas formulações da oligarquia Accioly, desejosa de ampliar suas bases de aceitação (Barros da Ponte, 1990).

A transformação gradativa da cidade cearense em metrópole ocorre reproduzindo ou exacerbando características semelhantes às demais cidades brasileiras: crescimento desordenado e convivência simultânea de modernização e pobreza. É sobretudo a partir de 1970 que Fortaleza experimenta um processo de verticalização e descentralização de atividades de comércio de lazer. Esta tendência é acentuada nas décadas seguintes, ocasião em que a cidade consolida sua condição de metrópole com vocação para o turismo.

Fortaleza hoje possui grande densidade populacional, com mais de dois milhões de habitantes e riqueza concentrada nos setores comercial e turístico. O turismo representa uma das maiores fontes geradoras de renda, sendo objeto de investimentos públicos de ordem municipal e estadual.

A ampliação da rede de hotéis e a oferta de serviços respondem a uma fase atual da cidade, marcada por diversificação de atividades e oferta de bens de lazer e cultura. $\mathrm{O}$ incentivo cada vez maior ao turismo em Fortaleza vem criando um novo discurso de exportação de imagens a serem propagadas e absorvidas para consumo. Duas perspectivas de apre- 
sentação da cidade marcam esta dinâmica: a "história" da cidade, com seus costumes e produção artesanal, e a sua natureza, exemplificada principalmente nas praias. Enquanto a primeira remete ao reforço e "re-invenção" de costumes e valores, a segunda propõe uma espécie de paraíso fortalecido na visão de uma região privilegiada por belezas naturais. É nesse contexto que as propostas de revitalização ganham maior densidade.

A descentralização gradativa de atividades explicitou as diferenças de zonas por oferta de serviços e equipamentos, gerando discursos sobre as desigualdades e a necessária recuperação de espaços tidos anteriormente como nobres, como é o caso do centro da cidade. Duas formas discursivas que sintetizam, de modo não-antagônico, falas e concepções sobre a cidade de Fortaleza serão tomados como referência: o discurso da preservação e o discurso da transformação planejada.

\section{O discurso da preservação: nostalgia e crítica social}

Não há recanto de Fortaleza, por mais humilde, ou mesmo modificado pelo progresso, que não traga à lembrança uma velha ocorrência oculta nas dobras do passado (Otacílio Azevedo, Fortaleza descalça, p. 214).

A idéia de uma cidade desfigurada pelas modificações rápidas, explicitadas na criação de grandes avenidas e transformações de zonas residenciais em espaços que visam racionalizar atividades de comércio e lazer, está presente em muitas formulações que atravessam o senso comum, integrando discursos também proferidos por urbanistas. As alterações rápidas são percebidas como uma espécie de rolo compressor que dá à cidade uma feição homogeneizadora destituída de tradições culturais.

O discurso da preservação tem características nostálgicas presentes, muitas vezes, na fala dos habitantes. O que a cidade "não é mais" torna-se 
a tônica de percepções que, muitas vezes, fazem do passado um momento de felicidade perdida. Discursos de romancistas ou cronistas tentam expressar a idéia de um passado não só perdido como radicalmente diferente da época contemporânea. Assim, o escritor e jornalista Blanchard Girão narra o que seriam as memórias afetivas da cidade de Fortaleza: "Paris era a capital do mundo e Fortaleza era uma cidade clonada, espécie de miniatura da capital francesa, com seus cafés e suas construções art nouveau" (jornal O Povo, 12/4/99). Prosseguindo em suas memórias, o autor situa personagens e costumes que marcam a história de Fortaleza no início do século, em contraste com as práticas emergentes à época:

Agora temos a Fortaleza lanque, americanizada, de frouxos blusões e bermudas berrantes, de coca-cola e fastfoods, de sandwishes e cursos de inglês em cada ponto. Uma Fortaleza de espigóes barrando o vento marinho, ocupando espaços, na trilha da arquitetura que exportou de Nova lorque pelo mundo ocidental. Uma cidade que se conduz pelos modismos ditados pela televisão, macaqueando costumes estranhos, falando com sotaque diferente do nosso, dançando música de discoteca, até imitando outros hábitos condenáveis que nos chegam por todos os meios de jato ou pelos satélites.

Também o escritor Otacílio Azevedo personifica a cidade para narrar as mudanças que se avizinham naquele momento:

Moça pobre mas vaidosa, Fortaleza ensaiava os primeiros passos nos caminhos do comércio internacional, passando da renda da almofala para a renda francesa, mandando buscar os melhores figurinos de Paris," casimira da Inglaterra, usando manteiga "Le Pelletier" e "Betel Freres" - enfim, procurando divertir-

7 A evocação feita a cidades européias coaduna-se com as reformas urbanas vividas na França e Inglaterra, países que tinham mais contatos com as cidades brasileiras. Fortaleza contava à época com a presença de capitalistas, técnicos e firmas inglesas e francesas que influenciavam projetos arquitetônicos (Rogério Ponte, 1993). 
se e mostrar-se nos saraus e festas, cinemas e igrejas.

Em seguida, o autor anuncia os "primeiros passos" rumo ao que viria a configurar-se como cidade moderna: "Pobrezinha descalça, ainda, mas já sonhando com as primeiras calçadas de pedra - o calçamento desigual e áspero, prenunciando as ricas futuras sandálias de asfalto" (Azevedo, 1992, p. 26).

O tom nostálgico dos cronistas aparece de forma mais sutil em discursos que preconizam o efeito das metamorfoses rápidas que ocorrem na cultura e estrutura urbana da cidade. Por ocasião do aniversário da cidade de Fortaleza, em 1979, o arquiteto Gerson castelo Branco afirma que Fortaleza, aos 271 anos, é uma cidade sem identidade. Segundo suas palavras:

Ao contrário de capitais como Recife e Salvador, Fortaleza não passou pelo processo revitalizador de suas vilas mais antigas, de suas casas seculares hoje vistas com outros olhos. Ao invés disso, o que temos de patrimônio arquitetônico está espalhado. As pessoas são má (sic) informadas e não valorizam a cultura da terra (Cf. Silva Araújo, Tribuna do Ceará, 8/4/79).

Outra perspectiva de crítica social ao crescimento de Fortaleza é consonante com a idéia já tematizada por intelectuais brasileiros de que a cidade reflete as desigualdades sociais sendo, nesse sentido, local de exclusão e pobreza. Em Fortaleza, a cidade seria também reflexo de uma estrutura baseada na concentração de propriedade agrária. A urbanização pauperizada responderia pela existência de favelas, provocada por um antagonismo social indutor de diferenças entre a cidade legal e a cidade real. As formulações desta crítica social questionam, inclusive, a prioridade conferida às obras turísticas: Praia de Iracema, Ponte Metálica, Centro Cultural Dragão do Mar e Aeroporto. No âmbito de uma postulação crítica a respeito das intervenções urbanas, destaca-se a percepção de que estas reproduzem a chamada "Fortaleza dos pobres e Fortaleza dos ricos". 


\section{O discurso da transformação planejada: investimento e revitalização}

A década de 1990 é profícua em acenos à reforma urbana presente na fala de planejadores e gestores da cidade. $\mathrm{O}$ argumento justificador das intervenções denominadas de "revitalização" se baseia na existência da violência, depredação de antigos prédios, mau uso dos espaços e, enfim, descaso com a preservação do patrimônio expressivo da história da cidade. Trata-se de uma proposta que toma o centro ${ }^{8}$ da cidade como local por excelência de recuperação da dignidade do passado.

A chamada decadência do centro é percebida por alguns sinais: perda de habitabilidade, presença de "marginais", prostituição e desorganização das atividades de comércio. A própria transferência, para outros espaços, de edificações que abrigavam os representantes do poder político e eclesiástico tais como o Palácio do Governo do Estado, a Assembléia, o Palácio do Bispo e a Câmara dos Deputados, concorre para tornar o centro "anacrônico", em oposição à vitalidade de outras zonas da cidade. A opinião de profissionais do urbanismo sobre a necessidade de intervenção no centro da cidade, difundida pelo jornal O Povo de 8/11/99 por ocasião do Fórum Fortaleza 2000, converge em muitos pontos. Trechos das propostas difundidas por arquitetos que têm atuação relevante no espaço urbano são significativos para indicar os sentidos presentes na idéia de revitalização. As propostas anunciadas são as seguintes: "Recuperação definitiva, radical e corajosa do centro urbano de Fortaleza com a participação indispensável dos governos local, estadual e federal, que têm em toda a sua história acumulada grande responsabilidade sobre a decadência do local' (Fausto Nilo).

Preservar os locais históricos que também estão sendo degradados. O centro da cidade já é uma demonstra-

8 O centro é caracterizado como local que congregava anteriormente as atividades de comércio, sendo também espaço aglutinador de atividades administrativas. A palavra centro e a palavra cidade têm uma homologia no discurso nativo, pois era no centro que as "coisas aconteciam". 
ção de desprezo total pela história da cidade. De um momento para outro o que é que se fez? Se matou um rio que foi o nascedouro da cidade, o Pajeú, se matou a presença do forte de nossa Senhora de Assunção que tem relação histórica (Jorge Neves).

A identidade da cidade deve ser feita a partir de sua diversidade e não de sua homogeneidade. Aí entraria a unidade do bairro como unidade de planejamento. O bairro deveria ser respeitado em sua identidade física a partir dos costumes e tradições de sua população, de suas festas sagradas, artistas e de toda cultura (José Lemenhe).

É necessário a

evolução do conhecimento sobre a cidade e sua história. Não partir do pressuposto de que o turista que vem para Fortaleza não se interessa pela cultura. Valorizar as avenidas e prédios históricos e disponibilizar material explicativo sobre a cidade. Você passa por aqueles prédios e não sabe a história de nenhum deles (José Lemenhe).

É preciso controlar a verticalização, hoje presente nos bairros Aldeota, Papicu e Meireles. Aumentar as áreas verdes públicas (Joaquim Cartaxo).

Os discursos remetem à idéia de preservação, controle, revitalização, apresentando variadas, porém convergentes, sintonias entre a cidade e sua história. Um ponto comum entre as diferentes perspectivas é a busca de recomposição das perdas referentes ao desaparecimento ou degradação de edificações urbanas, através de formas mais efetivas de intervenção.

Um outro momento expressivo de discussão sobre a revitalização do centro da cidade aconteceu por ocasião do Fórum Adolf Herbster - pen- 
sando o futuro do coração de Fortaleza. A idéia de reunir lideranças e empresários, representantes políticos e especialistas na temática urbana teve como um dos objetivos colher propostas de intervenção nas zonas centrais. Segundo a opinião dos idealizadores, presente no folder da programação geral do evento, o Fórum foi pensado como um espaço para o debate de temas ligados ao planejamento e ao desenvolvimento urbano de Fortaleza. A busca de experiências similares materializou-se na fala do primeiro conferencista do Fórum, secretário de urbanismo do Rio de Janeiro, que afirmou estar a capital carioca passando por um processo urbanístico que tinha como propósito manter a identidade do centro histórico da cidade (Jornal O povo, 13/4/99). O Fórum sobre Fortaleza, organizado pela Prefeitura Municipal, teve na realidade poucos desdobramentos efetivos, funcionando mais como alerta para se pensarem formas efetivas de reconstrução do centro da cidade. Embora os significados atribuídos à revitalização fossem distintos, prevaleceu no Fórum uma visão de unidade que poderia estar na proposta de congregação de espaços urbanos, incorporando acenos a uma estética da diversidade.

Além dos acenos à reconstrução do centro da cidade, outras propostas de intervenção urbana integram o discurso de planejadores e arquitetos. A idéia de construir uma perspectiva de equilíbrio entre diferentes atividades urbanas está bem presente na opinião do arquiteto Fausto Nilo:

Gosto da mistura de usos e estilos. Está provado que a cidade com especialização de funções está superada. $O$ indivíduo pega o carro se desloca para o trabalho e volta. Minha proposição é a de quadras com todos os equipamentos, tendo como exemplo Copacabana. O centro como lugar ag/utinador deve no entanto continuar. A gente conhece o lugar agradável pela presença de velhos (Entrevista concedida à autora em maio de 1999).

A intervenção planejada encontra também um de seus suportes na 
perspectiva de tornar a cidade habitável para os turistas. Trata-se de uma concepção que mantém com o passado um diálogo que poderia ser nomeado de invenção: valorizar o típico através de ícones alusivos à cidade. É sob o princípio de apresentação do típico que as práticas de turismo se movem, classificando tanto uma ótica de valorização da natureza como recuperação dos chamados costumes locais, exemplificados no artesanato e folclore. Nesse caso, o turismo pode ser visto como espaço de reinvenção da cidade, reproduzindo práticas sociais (visitação, consumo, etc.) com base em imagens semelhantes a cartões postais.

É importante salientar que, em 1992, a Embratur lança o Programa Nacional de Municipalização do Turismo. Este fato gerou políticas de desenvolvimento local motivando os municípios a buscarem suas "vocações" específicas. No espaço da municipalidade e do governo do Estado, a "vocação turística" de Fortaleza é mencionada, exemplificando as profundas articulações entre política, intervenção planejada e representações sobre a cidade.

Os discursos sobre a revitalização, acrescidos da perspectiva de controle sobre o destino da cidade, aparecem de modo singular durante as campanhas eleitorais municipais de 1996, ocasião oportuna de pensar e apresentar a cidade.

\section{Campanhas eleitorais e acenos ao futuro da cidade}

O momento da disputa eleitoral é particularmente profuso de discursos sobre o espaço urbano, e não seria exagerado afirmar que os pleitos municipais põem as cidades na vitrine, oferecendo ao público tanto imagens críticas negativas quanto visões de enaltecimento. A cidade, dissecada em seus espaços de mudança, deterioração, violência, desigualdade, harmonia e felicidade, aparece como uma espécie de caleidoscópio que emerge através de rituais discursivos presentes em diferentes propostas de intervenção urbana. 
As cidades, comumente evocadas em campanhas eleitorais, aparecem como potenciais objetos de uma intervenção política, sendo apropriadas como símbolo de poder e campo de investimento simbólico. Por conseguinte, a gestão da cidade não é mais vista como dependente de ações governamentais de caráter nacional, mas espaço relativamente autônomo e passível de múltiplas intervenções. Nas eleições municipais no Brasil, em 1996, a grande marca dos argumentos que contemplavam problemas urbanos referia-se à necessidade de realização de obras, vistas como parâmetro da boa administração. Uma espécie de linguagem corporificada nas edificações apontava a prova de que as "realizações" tinham seu estatuto de objetividade verificável por qualquer cidadão, sendo comprovação da boa administração política.

A "linguagem das obras" substituiu o descrédito na retórica oposicionista que marcou as eleições do período de reconstrução democrática. A credibilidade política materializada sobretudo no ato de "fazer", serviu de lema à campanha de 1996 do candidato às eleições municipais de Fortaleza, pelo PMDB, Juraci Magalhães, cujo slogan estava contido na frase: "Juraci faz". Trata-se de um argumento baseado na eficácia, como prova irrefutável de competência, criando um referencial importante para diferentes candidaturas. Mesmo os candidatos de oposição, ao criticarem as obras como expressão de privilégios de alguns cidadãos, desde que beneficiavam principalmente bairros mais favorecidos, não conseguiram sair deste significante já legitimado do "fazer" como expressão de uma gestão competente. A campanha de Juraci Magalhães foi paradigmática em relação a outras disputas eleitorais vigentes à época no País, no sentido de mostrar edificações urbanas, realizadas em seu primeiro mandato, como forma de capital político.

A outra candidata, apoiada pelo governo do Estado (PSDB) à prefeitura de Fortaleza, absorveu mais nitidamente o discurso da crítica social, apontando a necessidade de planejamento contrário à proliferação de obras urbanas, consideradas de "fachada". "Não podemos deixar Fortaleza ficar 
igual ao Rio de janeiro", repetia em vários de seus discursos a candidata à prefeitura de Fortaleza, Socorro França, referindo-se ao problema da violência e das desigualdades sociais. Em outra ocasião, a postulante ao executivo municipal afirmava: "Egoísmo, violência e baixa qualidade de vida é o que podemos esperar em doses cada vez maiores. Não é profecia, tudo isso já aconteceu em outras grandes cidades brasileiras nas quais as prefeituras cuidaram somente das obras e descuidaram das pessoas".

Os discursos que caracterizam mais nitidamente um espaço de oposição, configurado no Partido dos Trabalhadores ou no Partido Comunista do Brasil, mostram-se menos refratários a uma personificação da cidade, pondo em seu lugar a condição de cidadania como matriz essencial das possibilidades de intervenção. Os direitos dos trabalhadores, a valorização da cultura, a diminuição das desigualdades e a participação, aparecem como o lado da cidadania a ser construído. As representações sobre a cidade como espaço de liberdade e criação exprime-se aí mais fortemente, reproduzindo o pensamento de que o cenário urbano é o palco das mobilizações coletivas passíveis de promover mudanças.

Em Fortaleza, os contrastes sociais são enunciados através da radicalidade apontada entre a "cidade dos ricos" e a "cidade dos pobres", exemplo também recorrente nos demais discursos de campanha eleitoral, que buscavam explicitar os espaços de contraste, através dos problemas relativos a saúde, educação e habitação. Modificações políticas recentes, que marcam rupturas com oligarquias tradicionais nomeadas de "coronéis", fundamentaram opiniões sobre a necessária adaptação da cidade aos "novos padrões de modernidade".

Uma expansão crescente de equipamentos urbanos tem marcado a vida da cidade de Fortaleza nos últimos anos, subsidiando a construção de uma imagem de cidade em decurso de modernização e desenvolvimento. Os discursos políticos de campanha foram, assim, permeados por esta concepção que impunha a cada candidato a defesa ou ataque à lógica do 
empreendimento, considerado, para alguns, como imprescindível ao vigor dos tempos modernos.

Não é somente a ausência de serviços urbanos em sua objetividade que fundamenta o discurso denunciador. $\mathrm{O}$ momento eleitoral funciona como uma espécie de acerto de contas ou renovação de um pacto entre eleitores e representantes só efetivamente tornado público nesse momento. Definir o que a cidade não é, seja por um desvio de sua "natureza próspera" ou pela "falta de vontade política" dos seus governantes, dá subsídios a discursos que enfocam o tema das carências sociais, geralmente acompanhados de proposições de mudança e revitalização.

A explanação de problemas sociais, entretanto, não implica o sentimento nostálgico de impotência. Ao contrário do desencantamento próprio das reflexões presentes na literatura de Benjamin e Baudelaire, ambas marcadas pela impossibilidade de reação aos efeitos sem retorno da modernidade, as promessas de campanhas políticas são acenos permanentes à mudança. Neste caso, o desencantamento é substituído pela esperança não apenas baseada em discursos, mas também fundada pela "comprovação" da capacidade de realizar intervenções - as obras urbanas. As interpelações baseadas na valorização da cidadania e participação, utilizadas mais fortemente por partidos de oposição, mobilizam as esperanças de mudança nas formas organizadas e associativas da sociedade civil.

\section{Linguagens do passado e do presente}

Se as representações e práticas que se efetivam no contexto urbano ligam-se à lógica das intervenções e ao lugar ocupado por distintos atores sociais, é importante também pensar nas significações imaginárias que moldam o próprio conceito de cidade. Isso porque

as cidades, ao contrário dos povoados e pequenos municípios são plásticas por natureza. Moldâmo-las à nossa imagem: elas, por sua vez nos moldam por meio 
da resistência que aparece quando tentamos imporIhes nossa própria forma pessoal. Nesse sentido, parece-me que viver numa cidade é uma arte, e precisamos do vocabulário da arte, do estilo, para descrever a relação peculiar entre homem e material que existe na contínua interação criativa da vida urbana. A cidade tal como a imaginamos, a suave cidade da ilusão, do mito, da aspiração do pesadelo, é tão real, e talvez mais real, quanto a cidade dura que podemos localizar nos mapas e estatísticas, nas monografias de sociologia urbana, de demografia e arquitetura (Raban, apud Harvey).

É na instituição do imaginário e seus efeitos sobre as formas urbanas de intervenção que a cidade dialoga com seu passado. A tentativa de recuperação de algo perdido e a busca de liames temporais conduzem a discursos sobre o patrimônio, lugar por excelência de negociação entre passado e presente. O passado inventado pode acionar um tempo mítico, uma harmonia perdida ou uma relação com a natureza. Assim pensa Hewinson (1987), referindo-se a paisagens urbanas reconstruídas e reabilitadas, típicas da cidade de Londres, nomeadas pelo autor de manufatura da herança:

O impulso de preservar o passado é parte do impulso de preservar o eu. Sem saber onde estivemos, é difícil saber para onde estamos indo. O passado é o fundamento da identidade individual e coletiva; objetos do passado são a fonte da significação como símbolos culturais. A continuidade entre passado e presente cria um sentido de sequência para o caos aleatório e, como a mudança é inevitável, um sistema estável de sentidos organizados nos permite lidar com a inovação e a decadência. O impulso nostálgico é um importante agente do ajuste à crise, é o seu emoliente social, reforçando a 
Sociologias, Porto Alegre, ano 5, no 9, jan/jun 2003, p. 314-339

identidade nacional quando a confiança se enfraquece ou é ameaçada (Hewinson, apud Harvey, 1993, p. 85).

O diálogo com o passado é a busca de um referente comum, capaz de disciplinar dinâmicas sociais que parecem mostrar desequilíbrio. No espaço dos investimentos turísticos, a descoberta de "vocações" e "identidades" expressa um processo de redescoberta do mundo que Denis Cerclet nomeou muito apropriadamente de reencantamento (Cerclet, s/d). Segundo a percepção do pesquisador francês, o turismo é um instrumento de reencantamento do mundo, pondo em cena o valor dos patrimônios culturais e naturais que constroem a idéia de identidade.

A perspectiva de acenos à transformação da cidade de Fortaleza encontra forte relação com as administrações governamentais, incentivadoras por excelência do turismo, cujas pretensões baseiam-se na manutenção de um fluxo permanente de visitantes. Não é por acaso que este diálogo, indutor de uma invenção do passado, aparece agora de forma bem nítida.

O discurso nostálgico e o discurso da intervenção planejada e "revitalização" explicitam duas formas paradigmáticas de alusão ao passado, sendo o primeiro mais comprometido com a visão mitológica da busca das origens. Na versão nostálgica, o fluxo entre passado e presente parece inexistente, ancorando-se em um plano fundamentalista. A história dos princípios (onde tudo começou), constantemente evocada por ocasião do aniversário da elevação de Fortaleza à categoria de vila, em 13 de abril, torna a narração um eterno retorno ou reminiscência de um passado que não se cruza com o atual cotidiano. Festeja-se o aniversário e se relembra a história tal qual um ritual de consagração.

Em um outro sentido, a readaptação do passado aos novos tempos, através de acenos à "revitalização", supõe a possibilidade de construção de elos temporais dotados de narrativas múltiplas. Os apelos turísticos, as intervenções urbanísticas ou as projeções arquitetônicas buscam, cada qual a seu modo, fortalecer a identidade urbana, guardando o seu quinhão de 
passado. É nesse âmbito que a idéia de patrimônio suscita uma espécie de afinidade eletiva com a noção de mito que "tem a sua disposição uma massa ilimitada de significantes" (Barthes, 1989, p. 141).

Imagens dessa percepção de patrimônio podem ser encontradas mais recentemente em Fortaleza, a partir da criação de centros de lazer com referente em equipamentos que tiveram outras funções no passado: a Ponte dos Ingleses, ${ }^{9}$ o Estoril, ${ }^{10}$ o Centro Dragão do Mar. ${ }^{11}$ A tentativa é a de reinventar o passado, recuperando, de forma simbólica, a "história" do equipamento, introduzindo novos hábitos e pondo em destaque a dimensão estética.

Uma das ricas discussões sobre as formas de relacionar passado e presente encontra-se na polêmica entre os chamados modernos e pósmodernos. Enquanto para os primeiros, a ruptura com a tradição projetase em um tempo futuro, encontramos entre os pós-modernistas a valorização da diversidade de estilos, a mistura de tempos, nos quais o passado aparece como texto a ser citado sem a ordem hierárquica de prioridades. É essa mistura que tornaria a pós-modernidade vista como a era do pastiche, do simulacro, que tem na cidade contemporânea sua expressão mais evidente (Jameson, 1994).

Fortuna, refletindo sobre as ruínas da cidade e a transformação do cotidiano indaga: "Serão as ruínas, os monumentos e os museus manifestações espaciais e artefatos que decoram a cidade que habitamos, ou ao contrário, serão eles elementos históricos, artísticos e culturais que atualizam o passado e lhe dão vida?' (Fortuna, 1997, p. 131). Se a resposta à pergunta supera a visão essencialista do passado, há que se pensar nos fluxos históricos distintos, não restritos a dinâmicas locais, que estão tam-

9 Ponte construída por firma inglesa no início do século, restaurada em 1994 como zona turística. 10 Restaurante da época da Segunda Guerra, transformado em recanto boêmio.

11 Na perspectiva de Gondim (1998), a construção do Centro Dragão do Mar enquadra-se na perspectiva de um projeto que "pretende articular turismo, renovação urbana e política cultural" (p. 11). 
bém circunscritos às lógicas interativas mais amplas que os estudiosos designaram por globalização. Um dos exemplos dessa perspectiva de recomposição de imagens, tendo como referência a cidade a ser vista por "outros", está no turismo, em que o consumo opera como elemento importante e indutor de intervenções e programas políticos de longo alcance.

Os discursos construídos sobre a cidade respondem a diferentes momentos e interesses veiculados por diferentes atores sociais. Uma negociação entre o que se preserva e o que se modifica parece indicar o estabelecimento de formas variadas de comunicação, incluindo ajustes e conflitos que vão adquirindo nuances diferenciadas, conforme os tempos e atores envolvidos nos destinos da cidade. Observa-se, portanto, a existência de diferentes articulações estabelecidas entre a cidade e seu tempo. Diálogos temporais com o passado ou projeções de futuro são construídos não apenas como via para se pensar a formulação de uma identidade, mas sobretudo para revelar as características discursivas de atores urbanos na era contemporânea.

Por fim, gostaria de citar um personagem da rica literatura de Calvino que, a meu ver, contém a imagem metafórica da busca de algo que se perdeu no tempo.

Esse Marcolvado tinha um olho pouco adequado para a vida na cidade: avisos, semáforos, vitrines, letreiros luminosos, cartazes, por mais estudados que fossem para atrair a atenção, jamais detinham seu olhar, que parecia perder-se nas areias do deserto. Já uma folha amarelando num ramo, uma pena que se deixasse perder numa telha não Ihe escapavam nunca; não havia mosca no dorso de um cavalo, buraco no cupim numa mesa, casca de figo se desfazendo na calçada que Marcovaldo não observasse e comentasse, descobrindo as mudanças de estação, seus desejos mais íntimos e misérias de sua existência. 
Esse personagem anacrônico, presente no emaranhado da vida urbana, pode materializar a busca do passado. O que se perde e o que se busca no fluxo do tempo.

\section{Referências}

AZEVEDO, Otacílio. Fortaleza descalça. 2 a edição. Fortaleza: UFC, 1992.

BARTHES, Roland. Mitologias. Rio de Janeiro: Bertrand Brasil, 1989.

BERMAN, Marshal. Tudo que é sólido se desmancha no ar: a aventura da modernidade. São Paulo: Companhia das Letras, 1982.

CALVINO, Ítalo. Marcovaldo e as estações na cidade. São Paulo: Companhia das Letras, 1991.

CANCLINI, Nestor Garcia. Consumidores e cidadãos: conflitos multiculturais da globalização. Rio de Janeiro: Editora UFRJ, 1997.

CASTELLS, Manuel e BORJA, Jordi. As cidades como atores políticos. In: Novos Estudos Cebrap, 45, São Paulo, 1996.

CASTORIADIS, Cornelius. A instituição imaginária da sociedade. Rio de Janeiro: Paz e Terra, 1992.

DUBOIS, Claude Gilbert. O Imaginário da Renascença. Brasília: Edições UNB, 1995.

FEATHERSTONE, Mike. Cultura de consumo e pós-modernismo. São Paulo: Stúdio Nobel, 1995.

FORTUNA, Carlos. As cidades e as identidades: narrativas, patrimônios e memórias. Revista Brasileira de Ciências Sociais, São Paulo, ANPOCS, 33 (fevereiro), 1997.

GEERTZ, Clifford. O saber local: novos ensaios de antropologia interpretativa. Petrópolis: Vozes, 1999, p. 111. 
Sociologias, Porto Alegre, ano 5, no 9, jan/jun 2003, p. 314-339

GONDIM, Linda. O dragão do lazer e da cultura invade a praia de Iracema. V seminário de História da Cidade e Urbanismo, PUC/Campinas, 1416 de outubro, 1998.

GONÇALVES, José Reginaldo Santos. Os patrimônios culturais como gênero de discurso. IX Encontro de Ciências Sociais Norte/Nordeste, Natal, 1999.

HARVEY, David. A condição pós-moderna: uma pesquisa sobre as origens da mudança cultural. São Paulo: Loyola, 1989.

HARVEY, David. Espaços urbanos na aldeia global: reflexões sobre a condição urbana no capitalismo no final do século XX. Cadernos de Arquitetura e Urbanismo, Minas Gerais, PUC , 4 (maio), 1996.

HOBSBAWM, Eric e RANGER, Terence. A invenção das tradições. Rio de Janeiro: Paz e Terra, 1984.

JAMESON, Frederick. Espaço e imagem: teorias do pós-moderno e outros ensaios. Rio de Janeiro: UFRJ, 1994.

LAPLANTINE, François. Les trois voix de l'imaginaire. Paris: Editions Universitaire, 1974.

PONTE, Rogério Sebastião. Fortaleza Belle Époque: reformas urbanas e controle social 1860-1930. Fortaleza: Fundação Demócrito Rocha, 1993.

RIBEIRO, Ana Clara T. e GARCIA, Fernanda Sánchez. City Marketing: a nova face da gestão da cidade no final do século. In: REIS, Elisa; FRY, Peter e ALMEIDA, Maria Hermínia (orgs). Política e Cultura: visões do passado e perspec tivas contemporâneas. São Paulo: Hucitec/ANPOCS, 1996.

SIMMEL, Georg. A metrópole e a vida mental. In: VELHO, Octávio Guilhermo (org). O fenômeno urbano. Rio de janeiro: Editores Zahar, 1976. 


\section{Resumo}

O artigo, baseado em pesquisa que toma Fortaleza como referência, tem por objetivo pensar as diferentes conexões estabelecidas entre a cidade e seu passado. Considera que os discursos sobre a urbe estão circunstanciados a diferentes contextos e porta-vozes. Destaca, nesse sentido, a cidade pensada por romancistas, historiadores, políticos e profissionais do planejamento urbano.

As transformações recentes da cidade ensejam discursos voltados para uma comunicação entre passado e presente, que apresentam tanto lamentações sobre a desfiguração do espaço urbano como a busca de recompor a "história" da cidade, através de uma política de preservação daquilo que é considerado como patrimônio. Atualmente o incentivo cada vez maior ao turismo em Fortaleza vem criando um novo discurso de exportação de imagens a serem propagadas e absorvidas para consumo.

A recuperação do centro da cidade, dos antigos prédios e áreas de lazer responde a este fluxo de transformação e preservação que caracteriza não apenas Fortaleza, podendo, também, expressar um movimento que ocorre em diferentes cidades brasileiras.

Palavras-chave: cidade, tempo e espaço, discurso, patrimônio, disputa simbólica. 